\title{
“CORRELATIVE STUDY OF PLACENTAL THICKNESS WITH RESPECT TO THE GESTATIONAL AGE AND FETAL WEIGHT BY ULTRASONOLOGICAL EVALUATION"
}

Ravi. N, Pruthvi.
1. Assistant Professor, Department of Radiodiagnosis, Victoria Hospital Bangalore medical college \& Research Institute Bangalore.
2. Senior resident, Department of Radiodiagnosis, ESI Medical College, Rajajinagar, Bangalore.

\author{
CORRESPONDING AUTHOR: \\ Dr. Ravi. N, \\ Door no $612,5^{\text {th }}$ main $13^{\text {th }}$ cross \\ Near Syndicate Bank M.C layout, Vijayanagara \\ Bangalore-40 \\ E-mail: ravinigappa@yahoo.co.in
}

\begin{abstract}
Placental thickness plays an important role when the menstrual age is not known. Placental thickness increases linearly with gestational age. Placental thickness and fetal weights are closely correlated in most circumstances and it fallows nearly a linear pattern except during last few weeks of gestation. Determining the Placental thickness may be helpful in the diagnosis of some abnormalities; a thin placenta may be seen in cases of IUGR and thick placentas are noted in hydrops fetalis of varied causes.
\end{abstract}

INTRODUCTION: The purpose of the present study of measuring placental thickness at the level of umbilical cord insertion site was to assess the relationship between placental thickness with gestational age and fetal weight and also to assess the growth pattern of placenta with advancing gestational age.

\section{AIMS AND OBJECTIVES:}

1. Placental thickness can be measured as a new parameter for estimating gestational age of the fetus.

2. To assess the fetal weight with respect to gestational age of the fetus

3 .To assess the changing pattern of placental thickness

\section{MATERIALS AND METHODS}

SOURCE OF DATA: The study included 200 normal antenatal women referred from antenatal clinic at the Department of obstetrics and gynaecology, during the period of study from June 2006 to June 2008.

METHOD OF COLLECTION OF DATA: After taking a detailed history the antenatal women will be examined for placental thickness, gestational age and fetal weight ultrasonologically.

INCLUSION CRITERIA: The antenatal women of all gestational ages from 11 weeks to 40 weeks of gestation referred to department of radio diagnosis, for routine antenatal ultrasound.

THE EXCLUSION CRITERIA: Patients with PIH, diabetes mellitus, intrauterine growth restriction, hydrops fetalis, congenital malformations and twins. 
Polyhydramnios: Large amounts of amniotic fluid can greatly increase the uterine volume and thus the surface area of placenta resulting in thinning of placenta.

Placenta with morphological variations in size and shape like lobed placenta, succenturiate lobe, placenta membranacea and circumvallate placentas.

Placentas with variations in insertions of umbilical cord like marginal or battledore placentas and velamentous cord insertions were excluded from study.

Placentas with poor visualization of cord insertion site were also excluded.

Poor sonographic visualization of the placenta: Due to maternal obesity, posterior shadowing from fetal structures especially in late third trimester.

THE SCANNERS AND TRANSDUCERS USED: The grey scale real time ultrasonographic examinations were performed using a HP image point $\mathrm{hx}$ ultrasound scanner and the probe used for the study was $3.5 \mathrm{MHz}$ convex array transducer. Hard copy images of the case were acquired using thermal printer and photographs.

ETHICS: Ethical committee approval has been obtained.

\section{STATISTICS -}

STUDY DESIGN: A Prospective cross sectional study consisting 200 normal antenatal women.

STATISTICAL METHODS: The mean values of placental thickness, in mm, along with respective standard deviation (SD) were computed for each Gestational age from 11 weeks to 40 weeks. The 95\% Confidence Interval were also calculated. The Correlation and regression analysis has been carried out to quantify the relationship between the gestational age in weeks and Placental thickness in $\mathrm{mm}$. The Slopes were also compared for various placental positions and different Gestational age groups (11-40 and 11-35 GA).

The data collected in this study is analysed statistically by computing the descriptive statistics viz., mean, and SD. The statistical significance difference between the mean was tested using Mann-Whitney test. The correlation between gestational age \& placenta thickness and gestational age \& expected birth weight are computed. The respective data are plotted on the scattered diagrams and the best fit is shown with a straight line. The results are considered statistically significant whenever $\mathrm{p} \leq 0.05$.

STATISTICAL SOFTWARE: The Statistical software namely SPSS 10.0 and Systat 8.0 were used for the analysis of the data and Microsoft word and Excel have been used to generate graphs, tables etc.

\section{RESULTS -}

RELATIONSHIP BETWEEN GESTATIONAL AGE AND THICKNESS: Results of measurements of placental thickness at each week of gestational age from 11 to 40 weeks are shown in table.

It is observed that placental thickness gradually increases from approximately $11.4 \mathrm{~mm}$ at 11 weeks to $36.5 \mathrm{~mm}$ at 40 weeks of gestational age. 
From 11 to 36 weeks of gestation the placental thickness $(\mathrm{mm})$ almost match the gestational age in weeks thereafter from 36 to 40 weeks the placental thickness was lowered by 1 to $3 \mathrm{~mm}$. At no stage of pregnancy the normal placenta greater than $38 \mathrm{~mm}$.

RELATIONSHIP BETWEEN GESTATIONAL AGE AND PLACENTAL THICKNESS FOR DIFFERENT PLACENTAL LOCATIONS: Cases were categorized into two groups based on placental location.

Group 1: Anterior and lateral placentas combined

Group2: posterior and fundal placentas combined.

Correlation of mean placental thickness with calculated gestational age from 11 weeks to 40 weeks was obtained in each group separately.

The thickness of the placenta did not vary relative to the placental location.

The data show that the placental thickness was directly related to gestational age for both groups, with linear regression modeling yielding the fallowing equations

GROUP1: Placental thickness $($ in $\mathrm{mm})=0.9817 \times$ gestational age (in weeks) $+1.6126 \quad$ ( $\mathrm{r}$ $=0.9931), r=$ Pearson correlation coefficient.

GROUP 2: Placental thickness (in mm) = $0.9030 \times$ gestational age (in weeks) 2.3401( $\mathrm{r}=0.9919)$, $\mathrm{r}=$ Pearson correlation coefficient.

The relationship between placental thickness and gestational age in both the groups are similar in terms of Pearson correlation coefficient and also similar in terms of regression coefficient i.e. 0.9817 for group 1 and 0.903 for group 2 .

\section{DISCUSSION -}

CALCULATION OF GESTATIONAL AGE :The gestational age in first trimester from 11 to 13 weeks of pregnancy was determined by measuring CRL and calculations using Hadlock tables.46 Additional measurements are not more accurate than the CRL length in predicting age from 11 to 13 weeks and their use in conjunction with CRL does not further improve age estimation.47

The gestational age in second and third trimesters from 14 to 40 weeks of pregnancy was determined by composite fetal measurements of BPD, HC, AC, and FL4. Gestational age was computed by the ultrasound machine based on Hadlock tables by using regression equations from combination of measurements (computation software package). Four-parameter method used in second and third trimesters results in lowest variability estimates. Multiple variables do reduce uncertainty of the prediction, especially when measurements are made for the first time in the third trimester.

Hadlock postulated that multiple fetal measurements should be used in combination to provide a composite age estimate for several reasons:

The magnitude of the error in age prediction could be significantly greater when imaging or measurement error occurs when using a single parameter.

Normal fetuses may show measurements that are above or below the expected mean values at a given age for each parameter.

The process of plane selection of the fetal head, abdomen, and femur allows a detailed look at important anatomic structures and therefore facilitates detection of abnormalities in these areas. 
Sonographic estimates of gestational age are reported in cardinal numbers. Duration of pregnancy in weeks is recorded to the nearest menstrual week and reporting the gestational age to 1 or 2 decimal places was avoided.

The dissertation studies the relationship of placental thickness; in mm measured at the level of insertion of umbilical cord with advancing Gestational age in weeks. We obtained correlation of mean placental thickness with calculated gestational age and fetal weight from 11 weeks to 40 weeks.

THE SONOGRAPHIC TECHNIQUE OF PLACENTAL THICKNESS MEASUREMENT: The patient was scanned with a moderately distended bladder in supine position. The transducer was placed on the skin surface after applying the couple agent. The placental thickness in $\mathrm{mm}$ was measured at the level of cord insertion site. The transducer was oriented to scan perpendicular to both the chorionic and basal plates as tangential scan will distort the measurement of the thickness of the placenta.

CORD INSERTION: The identification of the cord insertion site is vitally important for obtaining correct measurements. The site is usually central but slightly eccentric position may be normal. The ultrasonic appearance of the cord insertion appears either as hypoechoic areas closest to the chorionic plate in the thickest portion of the placenta with a $v$ shape or as linear echoes emanating at right angles from the placental surface.

Placental thickness was calculated from the echogenic chorionic plate to placental myometrial interface. The myometrium and subplacental veins were excluded in the measurements.

All placental measurements were taken during the relaxed phase of the uterus as contractions can spuriously increase the placental thickness. The thickness increases during contraction due to distension of intervillous spaces by maternal blood. The length and surface of placenta can also increase due to distention of intervillous space. Placental thickness depends on amount of fetal blood, maternal blood and placental tissue.

PLACENTAL MYOMETRIAL INTERFACE: Correct identification of placental myometrial interface is important for proper measurements of placenta. Focal myometrial thickening due to contractions or myomata may spuriously suggest placental thickening but attention to the placental myometrial echogenicity difference should confirm that the placenta drapes over these regions of myometrial thickening36

Placental thickness value, in $\mathrm{mm}$, was calculated by averaging the three best measurements for each case.

ESTIMATION OF FETAL WEIGHT: Sonographic measurements of fetal body parts provide a direct way of assessing fetal size. Numerous formulas have been published for estimating fetal weight from one or more of the fallowing fetal body measurements: head (BPD, HC), abdomen (AC) and femur (FL). Other measurements, such as thigh circumference have been used as well53. Formulas that estimate fetal weight using three dimensional (3D) sonography and 3D magnetic resonance imaging have also been published.54

The accuracy of weight prediction formulas improves as the number of measured body parts increases up to three, achieving greatest accuracy when measurements of the head, abdomen and femur are used. There is no apparent improvement by adding the thigh circumference as a fourth measurement. 
Even when based on measurements of the head, abdomen and femur, sonographic weight prediction has a rather wide $95 \%$ confidence range of at least $\pm 15 \%$. Based on the abdomen and either the head or femur, the range is at least $\pm 16 \%$ to $18 \%$. Precision is considerably worse when only the abdomen is used.

A number of factors have been studied to determine their effect on accuracy of weight prediction .Accuracy appears to be less in fetuses that weigh less than 1000 grams than in larger fetuses. Over the rest of the birth weight range, however, accuracy is fairly constant.

SUMMARY: Sonographic measurement of placental thickness, at the level of cord insertion site and estimation of fetal weight is relatively simple and is clinically useful. It enables the evaluation and detection of placental abnormalities and intra uterine growth restriction that can significantly affect the management and outcome of pregnancy.

Placental thickness (in $\mathrm{mm}$ ) increases in a linear fashion with advancing gestational age (in weeks) and almost matching it from 11 - 35 weeks of gestation. It can be an additional indicator of estimating gestational age especially where the duration of pregnancy is unknown or uncertain.

It was observed that the relationship of Placental thickness with gestational age falls marginally and the rate of growth of Placental thickness decreased after 36 weeks of gestation. Determining the Placental thickness may be helpful in the diagnosis of some abnormalities; a thin placenta may be seen in cases of IUGR and thick placentas are noted in hydrops fetalis of varied causes.

Placenta grows throughout pregnancy, initial growth being much more rapid than that of the fetus .placental and fetal weights are closely correlated in most circumstances and it fallows nearly a linear pattern except during last few weeks of gestation.

The gestational age maintains linear relationship with gestational age up to 30weeks. .After 30 weeks the fetal weight gradually increases up to 38 weeks .The fetal weight and gestational age does not run significantly after 38 weeks. Determining that as placental thickness increases, the fetal weight also increases so that the placental growth directly influences the fetal weight.

LIMITATIONS OF THE STUDY: The present study is a cross-sectional study design, which is made up of observations on different individuals. It is not a true placental growth curve as these can only be obtained from serial measurements taken on the same patient throughout gestation. So, it may not provide a clear understanding in individual growth patterns. However, it is a reasonable approximation of a true placental growth curve. Longitudinal placental growth curves can be constructed from serial measurements taken on the same patient throughout pregnancy

ACKNOWLEDGMENTS: DEPT OF RADIODIAGNOSIS, AIIMS, B.G NAGAR. DEPT OF RADIODIAGNOSIS, BMC AND RI, BANGALORE.

\section{REFERENCES:}

1. Theera Tongsong, Pongrak Boonyanurak. "Placental thickness in the first half of pregnancy." J Clin Ultrasound. 2004; 32: 5: 231-234

2. Jauniaux E. "Placental ultrasonographic measurements: What can we learn and is it 
worth doing routinely?" Ultrasound Obstet Gynecol. 1992; 2: 241-242.

3. Ghosh A, Tang MH, Lam YH et al."Ultrasound measurement of the placental thickness to detect pregnancies affected by homozygous alpha thalassemia-1." Lancet. 1994; 344: 988-989.

4. Robert 0, Harris MD, Roberta 0, Alexander MD. Ultrasonography of placenta and umbilical cord. In: Peter W Callen, Ed. Ultrasonography in obstetrics and gynecology. $4^{\text {th }}$ edition. Philadelphia, WB Saunders Company, 2000, 597-625.

5. Matsumoto S, Nogomi Y, Ohkuri. "Statistical studies on menstruation: A criticism on the definition of normal menstruation." J Med Sci. 1962; 11: 294.

6. Nyberg DA, Finberg HJ. The' placenta, placental membranes and umbilical cord. In: Newburgh DA, Mahony BS, Pretorius DH, Eds. Diagnostic ultrasound of fetal anomalies. St. Louis, Mosby year book publishers, 1990, 623-675.

7. Crawford JM. "Vascular anatomy of human placenta". Am J Obstet Gynecol. 1962; 84: 1543.

8. Hamilton WJ, Boyd JD. "Trophoblast in human uteroplacental arteries". Nature. 1966; 212: 906.

9. Benirschke K, Kaufman P. Pathology of human placenta. Newyork, Springer-Verlas, 1990, 136-140

10. Moore Kt. The developing human $4^{\text {th }}$ edition. Philadelphia, W. B. Saunders Company, 1988, 104-130. 
TABLE -1 Relationship between Gestational age and Placental thickness

\begin{tabular}{|c|c|c|c|}
\hline $\begin{array}{l}\text { GESTATIONAL } \\
\text { AGE(WEEKS) }\end{array}$ & $\begin{array}{l}\text { NUMBER OF } \\
\text { CASES }\end{array}$ & $\begin{array}{l}\text { PLACENTAL } \\
\text { THICKNESS } \\
(\mathrm{mm})\end{array}$ & $\begin{array}{l}\text { 95\% CONFIDENCE } \\
\text { INTERVAL } \\
\text { (Upper-lower) }\end{array}$ \\
\hline 11 & 3 & $11.40+0.52$ & $11.03-11.77$ \\
\hline 12 & 6 & $12.00 \pm 0.00$ & $12.00-12.00$ \\
\hline 13 & 7 & $13.45 \pm 1.51$ & $12.44-14.47$ \\
\hline 14 & 7 & $14.00 \pm 0.77$ & $13.48-14.52$ \\
\hline 15 & 5 & $15.82 \pm 1.08$ & $13.48-14.52$ \\
\hline 16 & 7 & $16.09 \pm 1.14$ & $15.33-16.85$ \\
\hline 17 & 5 & $17.11 \pm 0.33$ & $16.85-17.37$ \\
\hline 18 & 4 & $17.67 \pm 1.03$ & $16.58-18.75$ \\
\hline 19 & 11 & $19.50 \pm 1.22$ & $18.79-20.21$ \\
\hline 20 & 7 & $20.58 \pm 1.44$ & $19.67-21.05$ \\
\hline 21 & 6 & $20.82 \pm 1.25$ & $19.88-21.66$ \\
\hline 22 & 11 & $22.53 \pm 1.30$ & $21.81-23.25$ \\
\hline 23 & 9 & $23.23 \pm 1.24$ & $22.48-23.98$ \\
\hline 24 & 4 & $25.00 \pm 0.93$ & $24.23-25.77$ \\
\hline 25 & 6 & $25.73 \pm 1.27$ & $23.87-25.58$ \\
\hline 26 & 5 & $26.63 \pm 1.51$ & $25.37-25.58$ \\
\hline 27 & 7 & $27.44 \pm 1.67$ & $26.16-28.73$ \\
\hline 28 & 6 & $28.50 \pm 0.93$ & $27.72-29.27$ \\
\hline 29 & 5 & $28.67 \pm 1.51$ & $27.09-30.25$ \\
\hline 30 & 4 & $29.14 \pm 3.24$ & $26.15-32.14$ \\
\hline 31 & 3 & $30.40 \pm 1.52$ & $28.52-32.28$ \\
\hline 32 & 7 & $31.11 \pm 1.90$ & $29.65-32.57$ \\
\hline 33 & 7 & $32.00 \pm 1.00$ & $31.33-32.67$ \\
\hline 34 & 4 & $34.29 \pm 1.25$ & $33.13-35.45$ \\
\hline 35 & 13 & $34.16 \pm 1.64$ & $33.37-34.95$ \\
\hline 36 & 12 & $34.65 \pm 1.73$ & $33.76-35.54$ \\
\hline 37 & 10 & $34.93 \pm 1.27$ & $34.19-35.66$ \\
\hline 38 & 10 & $35.07 \pm 1.39$ & $34.29-35.83$ \\
\hline 39 & 4 & $35.50 \pm 1.52$ & $33.91-37.09$ \\
\hline 40 & 2 & $36.50 \pm 2.12$ & $36.50-37.12$ \\
\hline
\end{tabular}

\begin{tabular}{|l|l|l|l|l|}
\hline PARAMETERS & NO. OF SUBJECTS & RANGE & MEAN & SD \\
\hline Gestational age (weeks) by USG & 200 & $11-40$ & 27.83 & 8.63 \\
\hline Placenta thickness (mm) & 200 & $11-38$ & 27.20 & 7.88 \\
\hline
\end{tabular}

In the present study, it is observed that the mean \pm SD of gestational age (weeks) by USG is $27.83 \pm 8.63$ with a range of $11-40$ weeks. The mean \pm SD of placental thickness is $27.20 \pm 7.88$ with a range of $11-38$ weeks. 
TABLE-2: Comparison between 11-35 weeks of Gestation age and Placenta thickness $(\mathrm{mm})$

\begin{tabular}{|l|l|l|l|l|l|}
\hline & Range & Mean & SD & T-value & P-value \\
\hline $\begin{array}{l}\text { Gestational } \\
\text { Age (weeks) by USG }\end{array}$ & $11-35$ & 24.67 & 7.67 & \multirow{2}{*}{0.100} & $>0.921$ \\
\cline { 1 - 4 } Placenta thickness (mm) & $11-37$ & 24.59 & 7.41 & & \\
\hline
\end{tabular}

T-value is obtained using Student's t-test

It is found that at 11-35 weeks of gestational age there is no statistical significance Between the mean difference of gestational age $(24.67 \pm 7.67)$ and placental thickness $(24.59 \pm 7.41)$, which indicates that there is an high degree positive Correlation between gestational age and placental thickness( $r=0.921$ ) which is significant i.e. $\mathrm{P}<0.001$.

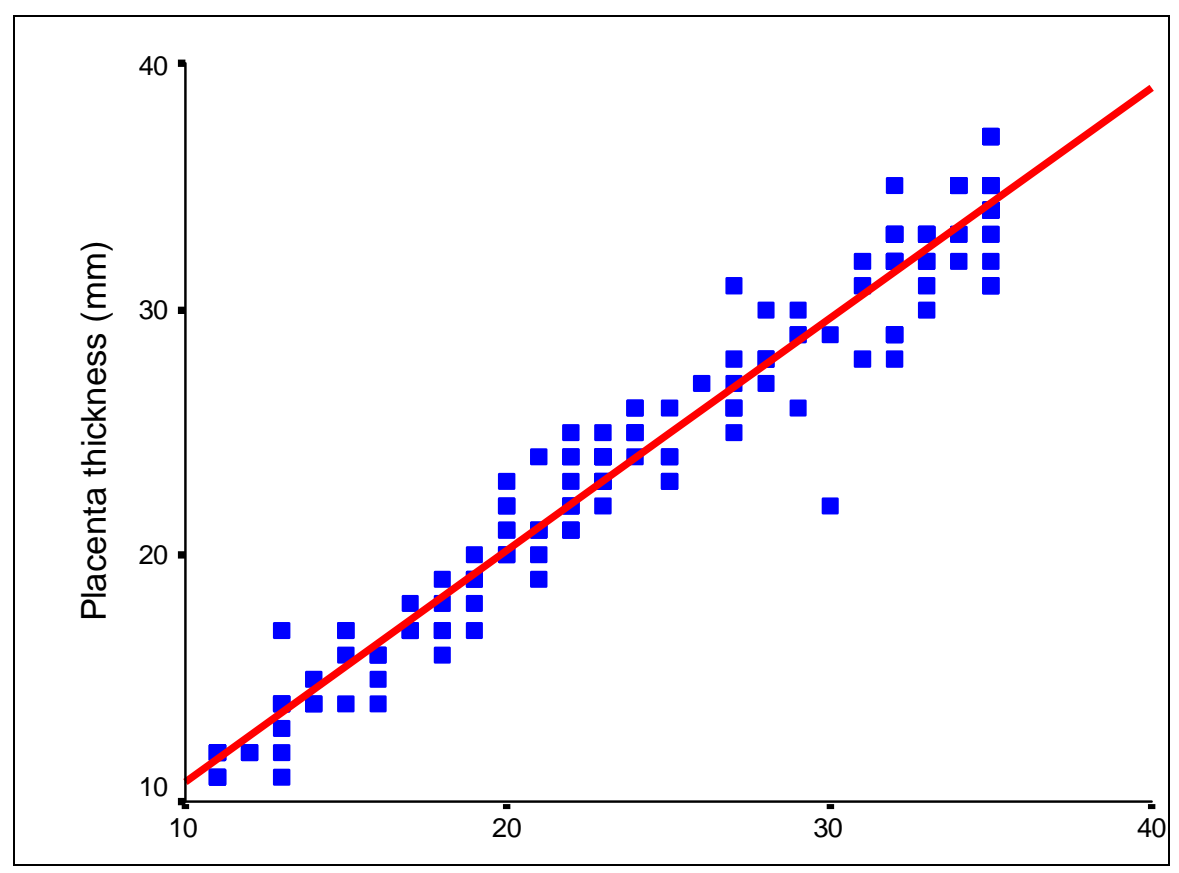

GRAPH - 1: GESTATIONAL AGE (11 - 35 WEEKS) BY USG

TABLE-3: Comparison between $>35$ weeks of gestation age and placenta thickness $(\mathrm{mm})$

\begin{tabular}{|l|l|l|l|l|l|}
\hline & RANGE & MEAN & SD & T-VALUE & P-VALUE \\
\hline Gestational & $36-40$ & 37.30 & 1.15 & & \\
Age (weeks) by USG & & & & 8.242 & $<0.001^{* * *}$ \\
\hline Placenta thickness (mm) & $31-38$ & 35.02 & 1.53 & & \\
\hline
\end{tabular}

*** Significant at $0.1 \%$ level. T-value is obtained using Student's t-test

After 35 weeks of gestational age there is high mean difference between gestational 
age (37.30 \pm 1.15$)$ and placental thickness(35.02 \pm 1.53$)$, which statically significant $(t=8.242$, $\mathrm{P}<0.001)$, which indicates that there is poor positive correlation.

Between gestational age and placental thickness( $\mathrm{r}=0.17, \mathrm{P}>0.235)$ which statistically not significant.

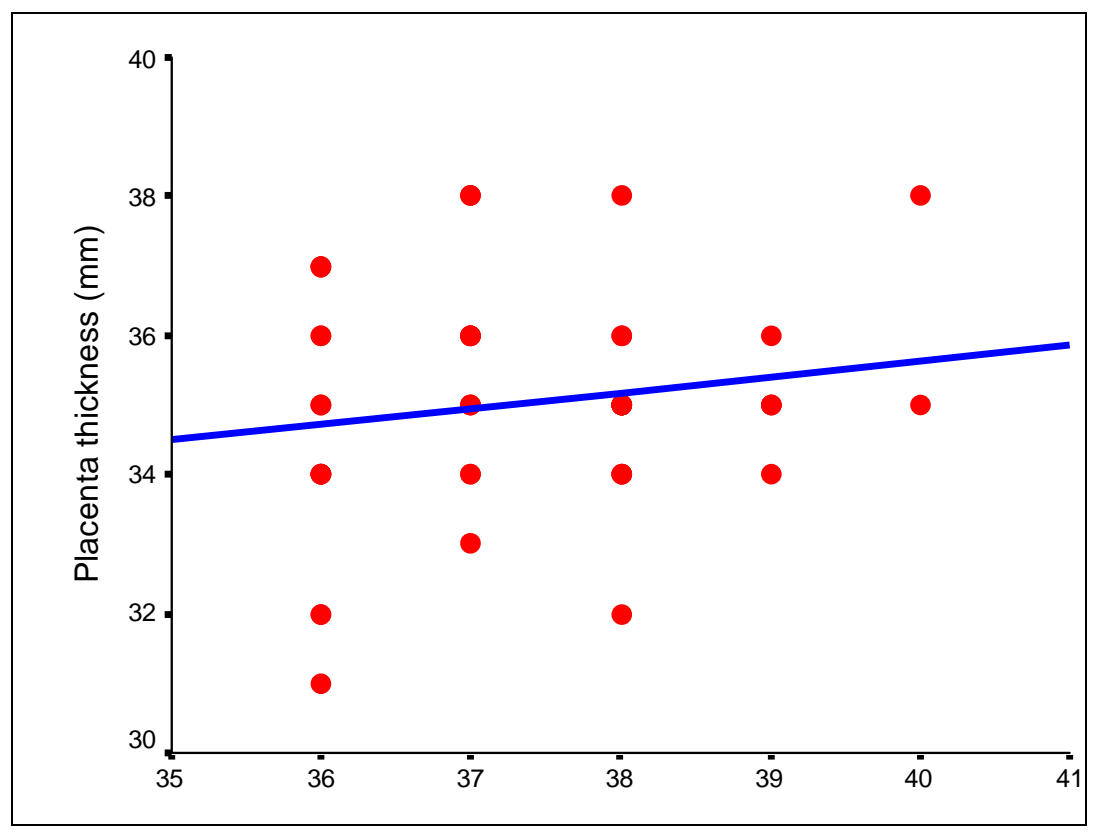

GRAPH - 2: GESTATIONAL AGE (>36 WEEKS) BY USG

TABLE-4:

\begin{tabular}{|l|l|l|}
\hline CORRELATION BETWEEN & $\begin{array}{l}\text { PEARSON'S } \\
\text { CORRELATION }\end{array}$ & P-VALUE \\
\hline Gestational age (11-25 weeks) and placental thickness & 0.98 & $<0.001^{* * *}$ \\
\hline Gestational age (> 36 weeks) and placental thickness & 0.17 & $>0.235$ (NS) \\
\hline \multicolumn{2}{|c|}{$* * *$ Significant at 0.1\% level. NS=Not significant }
\end{tabular}

In the present study it is observed that there is high positive correlation between the gestational age and placental thickness at 11-25 weeks. After 36 weeks poor correlation occurs between the placental thickness and gestational age.

For every week of increase in gestational age, there is an average increase of placental thickness by $0.8993 \mathrm{~mm}$. 


\section{ORIGINAL ARTICLE}

\section{TABLE 5: RELATION OF GESTATIONAL AGE AND FETAL WEIGHT}

\begin{tabular}{|c|c|c|}
\hline Gestational age (weeks) & Number of cases & Expected fetal weight(gms) mean \\
\hline 11 & 3 & 6 \\
\hline 12 & 6 & 12 \\
\hline 13 & 7 & 23 \\
\hline 14 & 7 & 38 \\
\hline 15 & 5 & 68 \\
\hline 16 & 7 & 106 \\
\hline 17 & 5 & 134 \\
\hline 18 & 5 & 180 \\
\hline 19 & 11 & 235 \\
\hline 20 & 7 & 290 \\
\hline 21 & 6 & 354 \\
\hline 22 & 11 & 410 \\
\hline 23 & 9 & 496 \\
\hline 24 & 4 & 590 \\
\hline 25 & 6 & 656 \\
\hline 26 & 5 & 790 \\
\hline 27 & 7 & 870 \\
\hline 28 & 6 & 930 \\
\hline 29 & 5 & 1160 \\
\hline 30 & 4 & 1328 \\
\hline 31 & 3 & 1485 \\
\hline 32 & 7 & 1678 \\
\hline 33 & 7 & 1863 \\
\hline 34 & 4 & 2089 \\
\hline 35 & 13 & 2495 \\
\hline 36 & 12 & 2638 \\
\hline 37 & 10 & 2854 \\
\hline 38 & 10 & 3019 \\
\hline 39 & 4 & 3235 \\
\hline 40 & 2 & 3459 \\
\hline
\end{tabular}




\begin{tabular}{|c|c|c|c|c|c|c|c|}
\hline & $\begin{array}{l}\text { GA } \\
\text { (weeks) }\end{array}$ & $\begin{array}{l}\text { No. of } \\
\text { subjects }\end{array}$ & Range & Mean & SD & F-value & P-value \\
\hline \multirow{4}{*}{$\begin{array}{l}\text { Gestational } \\
\text { age (weeks) } \\
\text { by USG }\end{array}$} & $\leq 30$ & 100 & $11-30$ & 20.25 & 5.32 & \multirow{3}{*}{356.097} & \multirow{3}{*}{$<0.001^{* * *}$} \\
\hline & $31-38$ & 93 & $31-38$ & 35.12 & 2.09 & & \\
\hline & $>38$ & 7 & $39-40$ & 39.29 & 0.49 & & \\
\hline & Total & 200 & $11-40$ & 27.83 & 8.63 & & \\
\hline \multirow{4}{*}{$\begin{array}{l}\text { Expected } \\
\text { fetal wt.(gms) }\end{array}$} & $\leq 30$ & 100 & $4-1329$ & 401.47 & 353.38 & \multirow{3}{*}{565.959} & \multirow{3}{*}{$<0.001^{* * *}$} \\
\hline & $31-38$ & 93 & $1160-3200$ & 2390.68 & 495.92 & & \\
\hline & $>38$ & 7 & $2490-3459$ & 2979.86 & 461.84 & & \\
\hline & Total & 200 & $4-35459$ & 1416.70 & 1108.82 & & \\
\hline
\end{tabular}

*** Significant at $0.1 \%$. F-value is obtained by ANOVA

Pair wise comparison between gestational age at different weeks and expected fetal weight

\begin{tabular}{|c|c|c|c|c|c|}
\hline Sl. No. & $\begin{array}{l}\text { Comparison } \\
\text { between }\end{array}$ & Mean & SD & z-value* & $\mathrm{P}$-value \\
\hline \multirow{2}{*}{1} & $\begin{array}{l}\text { Gestational age } \\
\text { (<30 weeks) }\end{array}$ & 20.25 & 5.33 & \multirow{2}{*}{9.25} & \multirow{2}{*}{$<0.001^{* * *}$} \\
\hline & $\begin{array}{l}\text { Expected fetal } \\
\text { weight (gms) }\end{array}$ & 401.47 & 353.38 & & \\
\hline \multirow{2}{*}{2} & $\begin{array}{l}\text { Gestational age } \\
\text { 31-38 weeks) }\end{array}$ & 35.12 & 2.09 & \multirow{2}{*}{11.797} & \multirow{2}{*}{$<0.001^{* * *}$} \\
\hline & $\begin{array}{l}\text { Expected fetal } \\
\text { weight (gms) }\end{array}$ & 2390.68 & 495.924 & & \\
\hline \multirow{2}{*}{3} & $\begin{array}{l}\text { Gestational age } \\
>38 \text { weeks) }\end{array}$ & 39.29 & 0.49 & \multirow{2}{*}{3.205} & \multirow{2}{*}{$<0.001^{* * *}$} \\
\hline & $\begin{array}{l}\text { Expected fetal } \\
\text { weight(gms) }\end{array}$ & & & & \\
\hline
\end{tabular}


ORIGINAL ARTICLE

\begin{tabular}{|l|c|c|}
\hline \multicolumn{1}{|c|}{ Correlation between } & $\begin{array}{l}\text { Pearson's } \\
\text { correlation }\end{array}$ & $\mathrm{p}$ - value \\
\hline $\begin{array}{l}\text { gestational age (upto30 weeks) } \\
\text { and fetal weight }\end{array}$ & 0.94 & $<0.001^{* * *}$ \\
\hline $\begin{array}{l}\text { gestational age (31-38 weeks) } \\
\text { and fetal weight }\end{array}$ & 0.90 & $<0.001^{* * *}$ \\
\hline $\begin{array}{l}\text { gestational age (>38 weeks) } \\
\text { and fetal weight }\end{array}$ & 0.70 & $>0.078$ (ns) \\
\hline
\end{tabular}

* Z-value obtained using Mann-Whitney test, *** Significant at $0.1 \%$ *** Significant at $0.1 \%$ level. NS=Not significant

It is found that up to 30 weeks the fetal weight Pearson correlation value is 0.94 suggest that high positive correlation exists. After 30 weeks of gestational age the fetal weight $P$ value is 0.90 suggest positive correlation. After 38 weeks of gestational age the $P$ value is 0.70 suggest that no correlation exists.

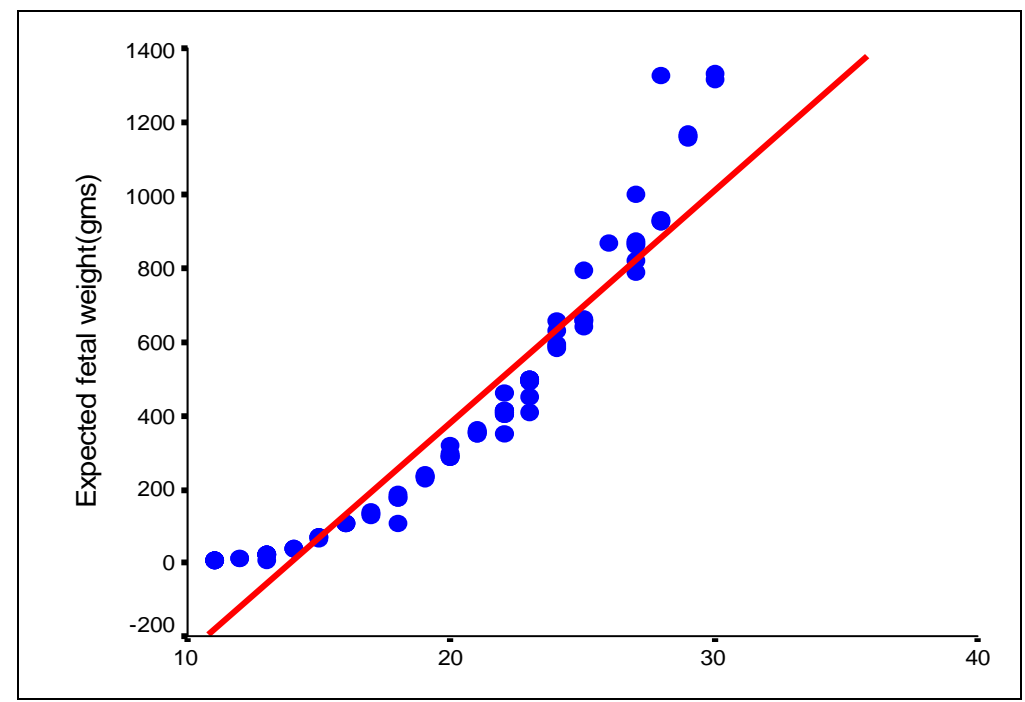

Graph - 3: Gestational age ( $<30$ weeks) by USG 


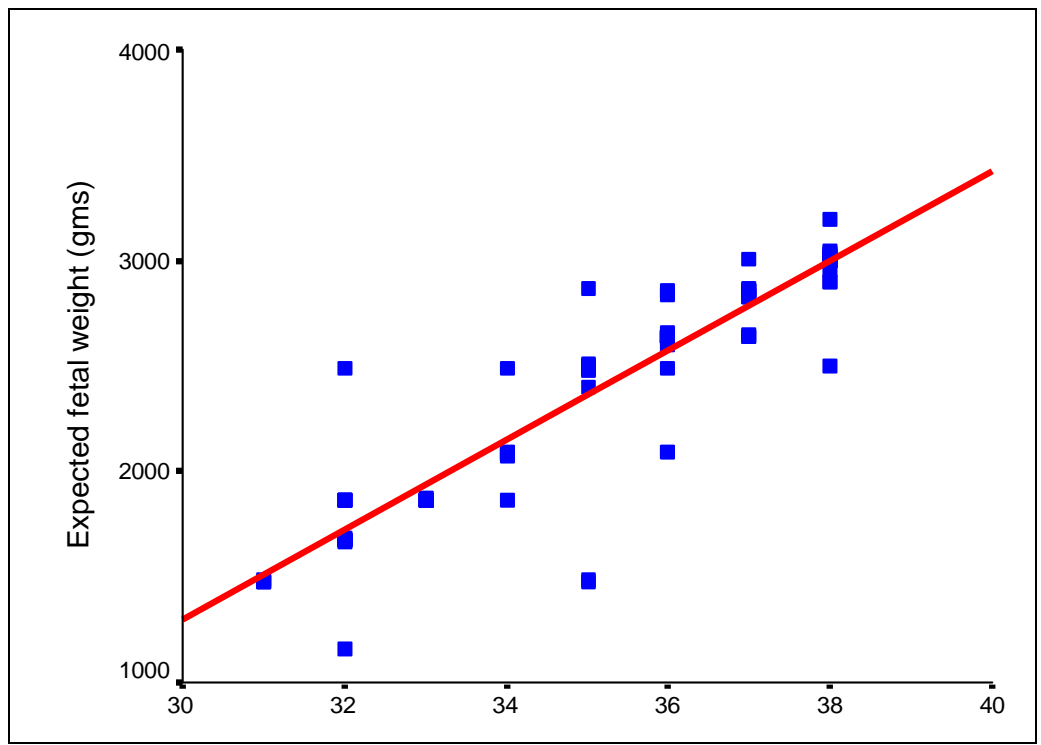

Graph - 4 gestational age (31-38 weeks) by usg

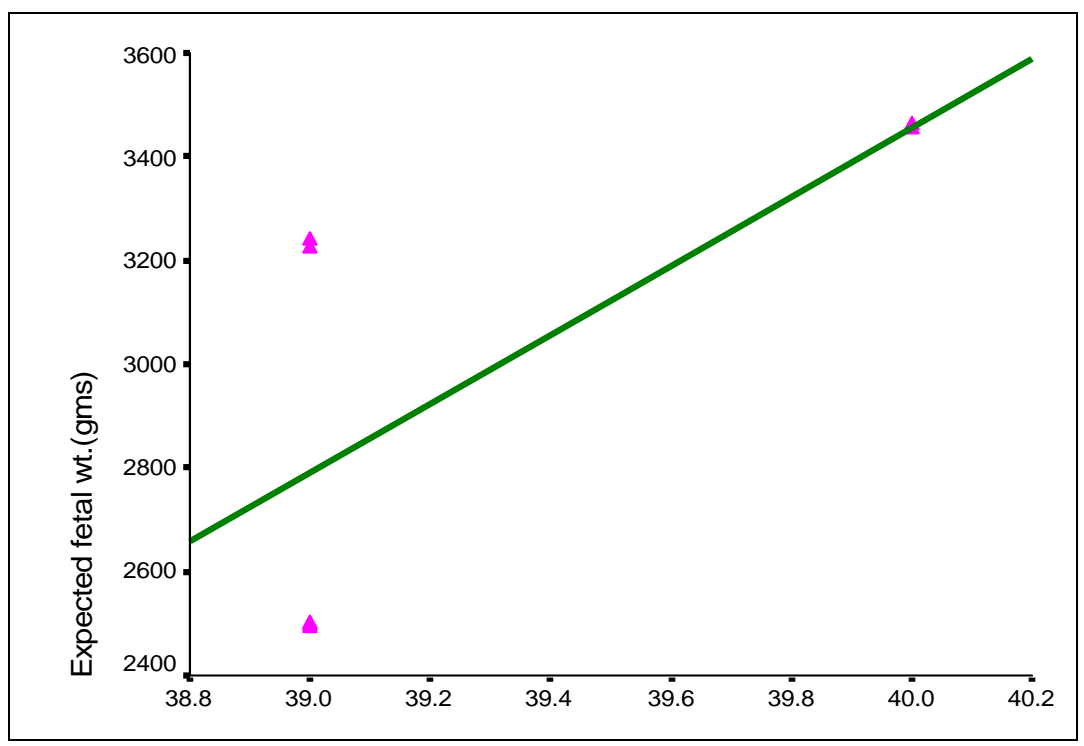

Graph - 5: Gestational age ( $>38$ weeks) by USG 